Theories \& Applications, the International Edition

Printed Version : (ISSN 2090-5262)

Online Version : (ISSN 2090-5270)

July 2014, Volume 4, No. 2 Pages (148 - 155)

\title{
The Role of Torque and Rotational Kinetic Energy to Perform Pike Sole Circle Backward To Handstand on Uneven Bars as an Indicator for Some of Simultaneous Exercises.
}

\section{Mohab Abd El-Razak Ahmed}

Assistant Professor, Department of Exercise and gymnastics training at the Faculty of Physical Education for Boys, Alexandria University

\begin{abstract}
The skill of Pike sole circle backward to handstand on uneven bars is considered as skill of difficulty (C), which can be developed into even higher difficulty $((F)$ and that happened by entering the flight on the same bar or moving between the two bars or through changing fists by entering windings or also it can be developed by not putting the foot on the bars.
\end{abstract}

The research aim: putting special exercises for The skill of Pike sole circle backward to handstand on uneven bars in the light of the most important biomechanical factors that effect on performance of this skill.

Tools of data collection:

A. two-dimensional television, using a speed of 100 cadre /s.

B. Analysis Program biomechanical with two-dimensional 2D to extract biomechanical variables Video Point V.2.5.

The results have shown the following:

Keeping the center of gravity away from the axis of rotation in the preliminary stage has a positive role in increasing speeds of joints, shoulders, thighs, before installing feet on the bar.

Bringing the center of gravity of the body from the axis of rotation by discouraging articular thighs by putting feet on the bar led to increase torque moment, inertia momentum, energy to spin for the body's center of gravity at the end and the beginning of rising swinging.

When you touch the feet of the bar, it must be with fingertip even reducing the friction force between the feet and the bar.

What the player acquired in the previous stages had a positive impact to reduce gravity in the process of lifting.

\section{Introduction}

$\mathrm{T}$ The device with uneven bars is considered as the hardest device in the training process because of its special nature and for its high physical requirements ,that's beside the courage and focus (2).all of these due to the improvement of the significant difficulties that have noticed in the Olympic and world tournaments in the shape of flight skills by leaving the bar and return again to the same bar, and skills between the two bars, or move with changing of fists .

The skills of the near bar are considered as one of the skills covered by the development, that happened by entering the flight on the same bar or moving between the two bars or through changing fists by entering windings .

This skill can also be developed by not putting feet on the bar. The skill of behind falling to pike sole circle backward to handstand on the uneven bars is considered as skill of difficulty $((\mathrm{C}$, which can be developed into even higher difficulty $((\mathrm{F})(1)$.

Mohamed Ibrahim Shehata has pointed in (2010) that the use of special exercise needs a high effort done by trainers and trainee that required compatibility designing exercises with model movement used in tournaments and knowing the exact details of the psychomotor skills of different time and power - and distance - and the direction of the muscle that work with skill in the working muscles to improve performance of skills. (8)

The skill of behind falling to pike sole circle backward to handstand on the uneven bars needs a flexibility in the articular shoulders and prolonging muscle .This helps to delay the installation of the feet on the bar at the preliminary stage, as well as strength in the abdominal muscles in order to maintain the status (V) during a performance of skill in the main stage and the final (6) (7). 
Therefore, the good preparation for this skill requires gradient steps in education and the use of auxiliary equipment and methods of necessary physical preparation in terms of flexibility and power (5).

The researcher noted that despite the importance of skilled non-availability of adequate information about the structure of the different phases of this skill and training programs, which paid for the study through kinetic analysis to identify the characteristics of biomechanical characteristics of its performance as a description, and that by relying on the technique of athletic players' high levels as a model when assessing performance skills.

The research aim: putting special exercises for The skill of behind falling to pike sole circle backward to handstand on the uneven bars $\mathrm{t}$ in the light of the most important biomechanical factors that effect on performance of this skill.

\section{The research sample:}

One of the Egyptian national team players that is outstanding in the performance on the device with the two different bars in height. Her length is $154 \mathrm{~cm}$, weight $53 \mathrm{~kg}$, age 18 years and five months at the time recording.

\section{Tools of data collection:}

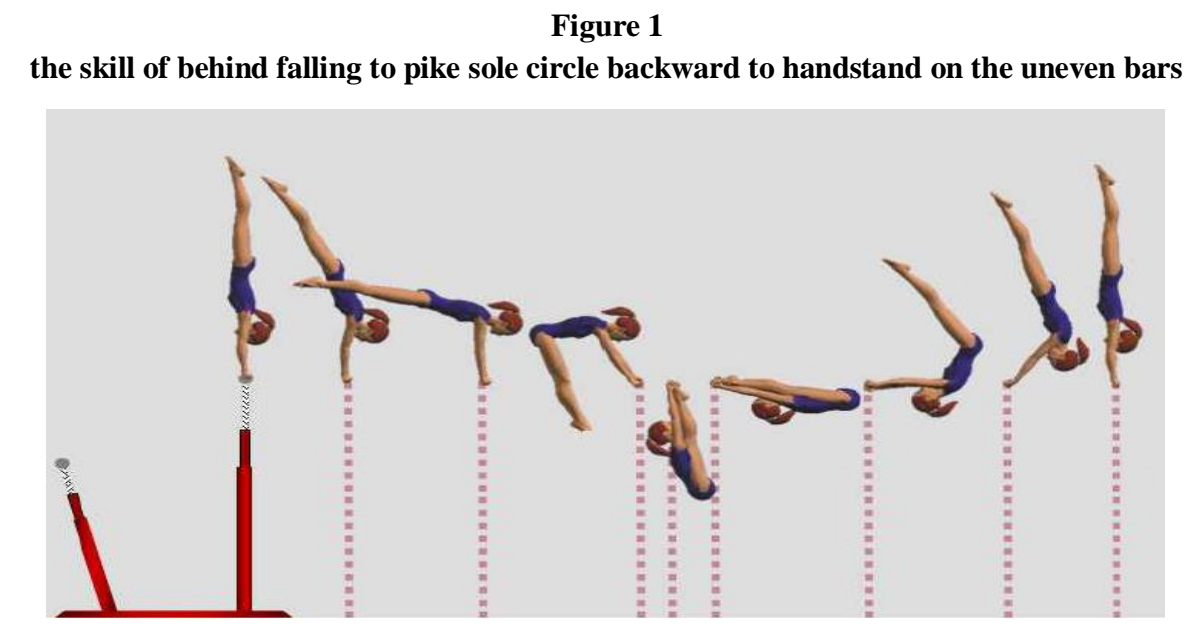

\section{Researcher has identified the stages of performance skill as the following:}

- Preliminary stage starts from standing on the hands on the bar even before the installation of the feet on the bar.

- The main stage begins from installing the feet on the bar till before leaving the feet of the bar.

- The final stage begins from starting to leave the bar till before a standing position on the hands.

The researcher has identified specific exercises on the following basis:

\section{The researcher used the following equations}

1. digital video camera "jvc", which is within the imaging system, two-dimensional television, using a speed of 100 cadre / $\mathrm{s}$ and with a special integrated analysis from the Faculty of Physical Education for Girls - Alexandria University .

2. International Arbitration law for Gymnastics for females edition (2013), in order to determine the performance level of skill under study degrees .

\section{Computer processor CPU P4}

4. Analysis Program biomechanical with twodimensional 2D to extract biomechanical variables Video Point V.2.5.

\section{Imaging and analysis:}

the player's Portrayed of the study sample during the performance of The skill of behind falling to pike sole circle backward to handstand on the uneven bars scientific method for imaging and television ( video ), the researcher has considered that the mechanical model of the player's body consists of (14)solid links (9), camera has been putted on height $(195 \mathrm{~cm})$ from the surface of the mattress and the distance off $(770 \mathrm{~cm})$, so that was the optical axis of the lens perpendicular to the plane of the spatial performance, that's the side view. And signs have been putted on the major joints of the body during the process of analysis as a reference.

Figure 1 
1 - Inertia equations in parallel axes (3) (4)

$$
\begin{aligned}
& \qquad I_{a}=\sum m_{i} r_{i}^{2} \\
& \text { where } \quad \begin{aligned}
I_{a} & =\text { moment of inertia about a given axis } \\
m_{i} & =\text { mass of a given particle } i \\
r_{i}^{2} & =\text { radius of rotation of the particle } i \text { to the axis of rotation }
\end{aligned}
\end{aligned}
$$

The unit of measurement is kg.m^2

2- Torque equation (3) (4)

$$
\Sigma T_{a}=I_{a} \alpha_{a}
$$

where $\Sigma T_{a}=$ the sum of the torques (net torque) about a given axis $I_{a}=$ moment of inertia about a given axis (rotational inertia)

$a_{a}=$ angular acceleration about a given axis, or change in angular motion of the system

\section{N.m is a unit of measurement:}

3 - Rotational motion Energy (3) (4)

$$
K E_{R}=1 / 2 I_{a} \omega_{a}^{2}
$$

where $K E_{R}=$ rotational kinetic energy (potential to perform work associated with angular motion)

$I_{a}=$ moment of inertia about a given axis

$\omega_{a}^{2}=$ angular velocity of an object about a given axis

The unit of measurement (joules)

4 - The amount of rotational motion (3) (4)

$$
L_{a}=I_{a} \omega_{a}
$$

where $L_{a}=$ angular momentum of the system (or quantity of angular motion) about a given axis

$I_{a}=$ moment of inertia of the system in motion about a given axis

$\omega_{a}=$ the linear velocity of the system about a given axis

The unit of measurement: $\mathrm{kg} \bullet \mathrm{m}^{\wedge} 2 / \mathrm{s}$

The Presentation and discussion of the results:

Table (1).

The time of the skill of behind falling circle by putting feet on the bar to stand on hands on the device with the uneven bars

\begin{tabular}{|c|c|c|c|c|}
\hline \multirow{2}{*}{ Percentage \% } & \multirow{2}{*}{ time } & \multicolumn{2}{|c|}{ cadres } & \multirow{2}{*}{ stage } \\
\cline { 3 - 5 } & & till & from & preparation \\
\hline 42 & 0.21 & 22 & 22 & main \\
\hline 24 & 0.12 & 34 & 34 & final \\
\hline 34 & 0.17 & 50 & \multicolumn{2}{|c|}{ The total skill time } \\
\hline$\% 100$ & 0.50 & &
\end{tabular}




\section{The time of the skill}

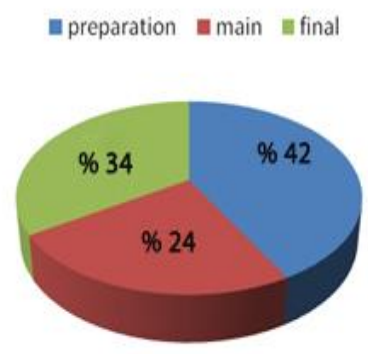

Shown in Table (1) that the preparation stage $(42 \%)$ and it was the longest compared to the major stage (24\%) and the gravity has the largest role in this disparity, In the preparation stage the player deceleration the body in case of the attracting of the Earth for the Lower Part to put feet on the casual bar in the direction of anti-gravity, which pulls the feet down and it took so large time $(0.21 \mathrm{~s})$ to be able to perform this prep part correctly when the center of gravity of the body (C.g) above the focal point or hand catching . and in the main stage when the (C.G) the center of gravity of the

Table ( 2)

body became below the pivot point in a bending position for the full body from thighs articular, the body circles quickly in the direction of performance and with the help of gravity so the time for this stage recorded almost the half the time of preparation stage, and in the final stage recorded a performance time much less than preparation stage, and more than the main stage as a result of work in the opposite direction of gravity to extend the articular thighs to get to a standing position on the hands .

Shifts of the body's center of gravity in the stages of skill under study Surface

\begin{tabular}{|c|c|c|c|}
\hline Value & Variables & \multicolumn{2}{|c|}{ Stage } \\
\hline 1.12 & The horizontal Displacement component & \multirow{3}{*}{\multicolumn{2}{|c|}{ preparation }} \\
\hline 2.55 & The vertical Displacement component & & \\
\hline 2.78 & resultant & & \\
\hline 0.57 & The horizontal Displacement component & \multirow{3}{*}{ starting } & \multirow{6}{*}{ 急 } \\
\hline 1.49 & The vertical Displacement component & & \\
\hline 1.6 & resultant & & \\
\hline 1.96 & The horizontal Displacement component & \multirow{3}{*}{ final } & \\
\hline 1.37 & The vertical Displacement component & & \\
\hline 2.39 & resultant & & \\
\hline 1.34 & The horizontal Displacement component & \multirow{3}{*}{\multicolumn{2}{|c|}{ The end }} \\
\hline 2.52 & The vertical Displacement component & & \\
\hline 2.85 & resultant & & \\
\hline
\end{tabular}

Shown in Table (2) private $(\mathrm{Cg})$ in the stages of skill under study in meter, the points, or the moment you start to prepare for the main phase rose from the Earth's surface ( $2.55 \mathrm{~m}$ ) where the body straightened above the focal point represented by casual bar, then the body move in circle back to decrease the horizontal and vertical components digitally to $(0.57,1.49 \mathrm{~m})$ and then the resultant displacement decreases at the start of the main phase to ( 1.6 $\mathrm{m}$ ) after it was in the beginning $(2.78 \mathrm{~m})$, and with the continued turnover the horizontal and vertical increase again and also their resultant, hitting the vehicle horizontal at the end of the main stage to $(1.96 \mathrm{~m})$ and up to the vehicle vertical $(1.37 \mathrm{~m})$, and that is produced by the movement of the vehicle body, which combines wheeling accidental posed by casual bar with a move away from the reference point .

It is worth mentioning countdown character of the vertical displacement component of the center of gravity of the body through the stages of skill as a result of rotation of the body and return to the starting point depending on the nature of performance in the skill under study were, respectively, according to the stages of performance : Preparatory stage the start of the main - the end of the Home : ( 2:55 pm ), ( $1: 49 \mathrm{~m}),(1.37 \mathrm{~m})$. 
Table ( 3)

Speeds of the body's center of gravity in the moments of the start of the stages of skill under study $\mathrm{m} / \mathrm{sec}$

\begin{tabular}{|c|c|c|c|c|}
\hline \multicolumn{3}{|c|}{ Velocities } & \multirow{2}{*}{\multicolumn{2}{|c|}{ Stage }} \\
\hline Resultant & Vertical component & Horizontal component & & \\
\hline 2.53 & $2.53-$ & $0.06-$ & prep & \\
\hline 12.69 & 12.58 & $1.64-$ & start & $\approx$ \\
\hline 19.56 & 19.16 & 3.94 & end & $\Xi=$ \\
\hline 2.4 & 0.52 & 2.35- & & \\
\hline
\end{tabular}

Seen from the table (3) that the outcome of the speed of the weight of the body in the preparation stage and the main character my head where the speed of the $(\mathrm{Cg})(2.53 \mathrm{~m} / \mathrm{s})$ in the preparatory stage, including speed component is equal to the same almost vertical. The total sum of speed $(12.69 \mathrm{~m}$ / s) at the start of the main phase and $(19.56 \mathrm{~m} / \mathrm{s})$ at the end

Table (4) of the stage, and the figures represent the growing character upward speed of the beginning of the preparatory stage and the end of the stage where the key goes the body down the level of the bar quickly incremental, as evidenced by the foregoing.

Angles and rotational velocities of the body's center of gravity at the start of the stages of skill under study

\begin{tabular}{|c|c|c|c|c|c|}
\hline \multicolumn{2}{|c|}{ Rotational velocities } & \multicolumn{2}{|c|}{ Angle displacement in the stage's start } & \multirow{2}{*}{\multicolumn{2}{|c|}{ stage }} \\
\hline Sixties degrees/s & Half radius degree/s & Sixties degrees & Half radius degree & & \\
\hline 89.095 & 1.555 & 7.85 & 0.137 & prep & \\
\hline 1019.865 & 17.8 & 94.6 & 1.651 & start & $=$ \\
\hline 1716.10 & 29.95 & 253.82 & 4.43 & end & \\
\hline 140.375 & 2.45 & 355.81 & 6.21 & & \\
\hline
\end{tabular}

Seen from the table (4) for angles and rotational speeds of gravity of the body that the angle of center of gravity of the body increased from the angle of the straight line and almost until the completion of a full cycle approaching (360 $\square)$, and was ( 7.85 ) in the preparation stage and then ( 94.6 ) and ( 253.82 ) in the two parts of main phase then ( 355.81 ) in the final, and was accompanied by an increase in angular velocity reached its peak at the end of the main part quickly reached (1716.1 degree / s ) at the completion of its curved body and center of gravity down to the level of the body in casual Parallel .

Since the values of the angles and speeds of joints of the shoulders and thighs working in a link so they cannot be neglected throughout the stages of skill as the main work for them and more importantly between the joints of the body has been put these valuable values one table, table ( 5 ).

Table (5)

Angles and rotational velocities of articular shoulders and thighs at the start of the stages of skill under study

\begin{tabular}{|c|c|c|c|c|c|c|}
\hline \multicolumn{2}{|c|}{ Rotational velocities } & \multicolumn{2}{|c|}{ Angle displacement in the stage's start } & \multirow{2}{*}{\multicolumn{3}{|c|}{ stage }} \\
\hline Sixties degrees/s & Half radius degree/s & Sixties degrees & Half radius degree & & & \\
\hline 151.8 & 2.65 & 179.3 & 3.13 & shoulders & \multirow{2}{*}{\multicolumn{2}{|c|}{ preparation }} \\
\hline-200.5 & -3.5 & 158.7 & 2.77 & thighs & & \\
\hline-484.6 & -8.45 & 115.2 & 2.01 & shoulders & \multirow{2}{*}{ start } & \multirow{4}{*}{ 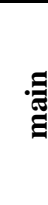 } \\
\hline-100.7 & -1.88 & 46.4 & 0.81 & thighs & & \\
\hline-309.4 & -5.4 & 110.6 & 1.93 & shoulders & \multirow{2}{*}{ end } & \\
\hline 1008.4 & 17.6 & 54.4 & 0.95 & thighs & & \\
\hline 693.3 & 12.1 & 171.9 & 3.00 & shoulders & \multirow{2}{*}{\multicolumn{2}{|c|}{ final }} \\
\hline 710.5 & -12.4 & 171.9 & 3.00 & thighs & & \\
\hline
\end{tabular}


shown from a table (5) it At a time when the angle of the shoulder straight almost (179.3 degree) in the preparation stage , the angle of the thighs $(158.7 \square)$ as a prelude to more bending to put feet on the casual bar, and in the same manner, and in the main stage closed the angle of the shoulders at the start and the end of the main report (115.2 $\square, 110.6 \square)$, respectively while increased the angle of the thighs as mentioned above, in the start and end of the main phase of the total $(46.4 \square, 54.4 \square)$, respectively, which the feet were based on the crossbars with gyro rear rapid body, and with the final stage all the corners of the body approached (shoulders, thighs) the angle straight line by the same amount (171.9 $\square$ ), and consistent speeds corner of the shoulders and thighs through the stages of skill under study to justify the large increase at the end of the main phase of the articular thighs by $(1008.4 \square / \mathrm{w})$ for the angular velocity at the start of preparation stage and the start of the main phase by (200.5 $\square-$ / w , - $100.7 \square$ / w ), respectively , and reflects the increasing accelerating clear of the thighs to complete the spin body curve around the axis, which represents a casual bar, and then complete the skill to an individual body to stand on the hands, but in the final stage of the skill, values had similar angles and speeds corner which indicates the body to work as one unit and not joints (Links) where the body straightened and the angular velocity of the major joints in the full skill under study .

Table (6)

Torque moment of inertia and rotational energy and angular momentum of the center of gravity of the body

\begin{tabular}{|c|c|c|c|c|c|}
\hline $\begin{array}{c}\mathrm{Kgm}^{2} / \mathrm{S} \\
\text { Motion quantity } \\
\end{array}$ & $\begin{array}{c}\text { Joules } \\
\text { rotational energy }\end{array}$ & $\begin{array}{c}\mathrm{Kgm}^{2} \\
\text { Inertia moment } \\
\end{array}$ & $\begin{array}{c}\text { N.m } \\
\text { Torque moment } \\
\end{array}$ & \multicolumn{2}{|c|}{$\begin{array}{c}\text { variable } \\
\text { stages }\end{array}$} \\
\hline 0.234 & 0.117 & 1.039 & 2.415 & \multicolumn{2}{|c|}{ preparation } \\
\hline-82.550 & -41.275 & 20.308 & 23.668 & start & \multirow{2}{*}{ 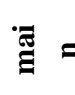 } \\
\hline 120.906 & 60.453 & 26.868 & -520.924 & end & \\
\hline-1.123 & -0.562 & 0.458 & -0.110 & \multicolumn{2}{|c|}{ final } \\
\hline
\end{tabular}

Is clear from Table ( 6) and from torque moment, and moment of inertia, and energy rotational, and angular momentum of the center of gravity of the body, reaching all the variables mentioned above to peak by the flowing respectively (-520.924 Nm) (Kgm2 26.868) (60.453 Joules) (Kgm2 / S 120.906) at the end of the main stage and through the table above, we find that all variables were similar in the hierarchy and this means that there is a relationship directly proportional between variables this is the result of energy resulting from the move away center of gravity of the body from the axis of rotation in a handstand during the preparation stage and then bring the center of gravity from the axis of rotation at the start of the main stage prior to the installation of the feet on the bar during the performance of the skill under study and who has had the role of a positive after the installation of the feet on the bar where he worked to increase all the variables at the end of the main stage and reflect these importance amounts of each of the angular velocity and the radian angle have big impact on the center of gravity of the body in the end of the main stage .

\section{Conclusions}

1. Keeping the center of gravity away from the axis of rotation in the preliminary stage has a positive role in increasing speeds of joints, shoulders, thighs, before installing feet on the bar.

2. Bringing the center of gravity of the body from the axis of rotation by discouraging articular thighs by putting feet on the bar led to increase torque moment , inertia momentum, energy to spin for the body 's center of gravity at the end and the beginning of raising swinging.

3. When you touch the feet of the bar must be with fingertip even reduce the friction force between the feet and the bar.

4. What the player acquired in the previous stages had a positive impact to reduce gravity in the process of lifting.

Recommendations for special exercises:

1. When you put special exercises for the elementary stage and during lifting body to back (to maintain the body straight with bend the articular shoulders while retaining the status bar vertically on the shoulders.

2. When you put the special exercises, it's important to delay putting the feet on the bar.

3. When you put the special exercises for the main phase, it's important to maintain pelvic bend down the bar until in the horizontal plane.

4. When you put the exercises for the final stage, it's important to straighten articular thighs and bend in the articular shoulders that after the arrival of the body in the horizontal plane and before get to a standing position on the hands. 


\section{Attachment}

The different proposed physical exercises for levels of the skill "pike sole circle backward to handstand on uneven bars" on the balanced beam, which includes 24 exercises by muscular work with Contractions centralized and decentralized for working muscle groups mainly in the skill which the subject of research, when designing, it has been relied on what has been Extracted from the properties of bio kinematics and bio kinetics In the previous parts of research.

\section{And the exercises spread over the stages as follows:}

- Six exercises for the stage "Stand on your hands until put the feet on the bar", preliminary stage.

- Twelve exercises for the stage "from putting the feet on the bar until leaving the feet of the bar", the main stage.

- Six exercises for the stage "from leaving the feet of the bar until handstand", the final stage.

When applying, we must consider controlling the doses which include volume, intensity and strength of training according to the state, weight and length of the player.

\section{The exercises of preliminary the stage:}

1- "Handstand above low bar" Leaning your body forward with shoulders stability above the bar.

2- "Handstand above low bar" leaning your body down with hip flexion at the horizontal level to put the feet on the bar and down on the mattress with retain the body situation curved.

3- "Long sitting. Hold horizontal stick in front of the body" leaning your body forward and down for passing the stick behind the stick.

4- "Torso Bend above the balance beams" extend the knees with press.

5- "Torso Bend and your back face the fixed horizontal bar in the wall" leaning the body and press.

6- "Torso Bend and your back face the fixed horizontal bar in the wall" leaning the body and press.

\section{The exercises of the main stage:}

1. "Standing above Mini Trampoline and your hands straight forward to catch low horizontal bar and your attached to the bar with loops "push by the feet to make the body at horizontal level with hip flexion to put the feet on the bar.

2. "Standing above Mini Trampoline and your hands straight forward to catch low horizontal bar and your attached to the bar with loops "Push by the feet to make the body at horizontal level with hip flexion to put the feet on the bar to make back flip (leant).
3. "Standing above Mini Trampoline and your hands straight forward to catch low horizontal bar and your attached to the bar with loops "push by the feet to make the body at horizontal level with hip flexion to put the feet on the bar to make back flip.

4. "hand standing on low horizontal bar with loops in a straight body and your feet are down "swing backward with hip flexion to put the feet on the bar (leant).

5. "hand standing on low horizontal bar with loops in a straight body and your feet are down "swing backward with hip flexion to put the feet on the bar.

7- "hand standing on low horizontal bar with loops in a straight body and your feet are down "Swing backward with hip flexion to put the feet on the bar to make back flip by putting the feet (leant).

8- "hand standing on low horizontal bar with loops in a straight body and your feet are down "swing backward with hip flexion to put the feet on the bar to make back flip by putting the feet.

9- "hand standing on low horizontal bar with loops in a straight body and your feet are down " swing backward above the horizontal level then hip flexion to put the feet on the bar to make back flip by putting the feet (leant).

10- "hand standing on low horizontal bar with loops in a straight body and your feet are down "Swing backward above the horizontal level then hip flexion to put the feet on the bar to make back flip by putting the feet.

11- "Hold the pike by putting the feet on the bar" swing the body with keeping the feet on the bar (leant).

12- "parallel resting on parallel bar "swing backward above the horizontal level then hip flexion to put the feet on the bar to make back flip by putting the feet (leant).

13- "Parallel resting on parallel bar "swing backward above the horizontal level then hip flexion to put the feet on the bar to make back flip by putting the feet (leant).

\section{The exercises of the final stage:}

1. "Pike Sole with straight hands backward when the body on a mattress to hold a low bar and put your feet on this bar " a lift the body to up with opening hips angle to stand on the hands. With assistance .

2. On the back with hands and feet on floor bar from , the coach lifts the gymnast to handstand insisting on keeping the elbows straight and rotating the wrists (gradually more weight is transferred on 
the gymnast's am flexion)-return or drops in front support

3. "parallel resting on parallel bar" swing backward above the horizontal level then hip flexion to put the feet on the bar to make back flip by putting the feet to stand on the hands (leant).

4. “parallel resting on parallel bar" swing backward above the horizontal level then hip flexion to put the feet on the bar to make back flip by putting the feet to stand on the hands.

5. "parallel resting on parallel bar" swing backward to stand on the hands then down the body with keeping the shoulders above hip flexion to put the feet on the bar to make back flip by putting the feet to stand on the hands (leant).

6. "parallel resting on parallel bar "swing backward to stand on the hands then down the body with keeping the shoulders above hip flexion to put the feet on the bar to make back flip by putting the feet to stand on the hands.

References

1. Federation International Gymnastics (2013): Women's Technical Committee : Code of Point FIG , Switzerland ,P,42 95,96

2. -federation international gymnastic academy (2010) : technical preparation asymmetric bars level1,P (25)

3. -federation international gymnastic academy (2010) : theoretical biomechanical preparation level2,P (20-25, 32)
4. John McLester \& Peter St. Pierre: Applied Biomechanics CONCEPTS AND

CONNECTIONS, Thomson Wadsworth, 2008. , pp 174:187

5. Jack Carter \&Computer Outla:(1997): Development of Stalder and Sole Circle to Handstand, USA Gymnastics Magazine Online .

6. http://dev.usagym.org/pages/home/publications/u sagymnastics/1997/4/coachingcorner_stalder.pdf

7. John Wojtczuk(1997):Technical Preparation for the Back Stalder and Late Toe-On, USA Gymnastics Online

8. http://usagym.org/pages/home/publications/techn ique/1997/9/stalder2.pdf

9. Mickaël Begon(2009): Effect of hip flexibility on optimal stalder performances on high bar. Computer Methods in Biomechanics and Biomedical Engineering ,p 575-583

10. 8-Mohamed, A, SH. (2011): System of specific training for the Artistic Gymnastics (Men); founder, international Horas institution, the first edition, P.P (19).

11. Williams,M.8Lissner,H.R.(1977):Biomechanics of human motion ed.2 W.B Saunders co., Philadelphia , P.P.211,212. 